\title{
e-Health as the Enabler of Primary Care for Children
}

\author{
Michael Rigby, Grit Kühne and Shalmali Deshpande
}

\begin{abstract}
Information and communication technologies can transform how services can be and are delivered as has already happened in other arenas, such as civil aviation, financial services and retailing. Most modern health care is heavily dependent on e-health, including record keeping, targeted information sharing and digital diagnostic and imaging techniques. However, there remains little scientific knowledge base for optimal system content and function in primary health care, particularly for children. Models of Child Health Appraised (MOCHA) aimed to establish the current e-health situation in children's primary care services. Electronic health records (EHRs) are in regular use in much of northern and western Europe and in some newer European Union Member States, but other countries lag behind. MOCHA investigated the use of unique identifiers, the use of case-based public health EHRs and the capability of record linkage, linkage of information with school health data and monitoring of social media influences, such as health websites and health apps. A widespread lack of standards underlined a lack of research enquiry into this issue in terms of children's health data and health knowledge. Health websites and apps are a growing area of healthcare delivery, but there is a worrying lack of safeguards in place. The challenge for policy-makers and practitioners is to be aware and to lead on the innovative harnessing of new technologies, while protecting child users against new harms.
\end{abstract}

Keywords: Health information and communication technologies; child health; electronic health record; apps; websites; e-health

\footnotetext{
(C) European Commission. Published by Emerald Publishing Limited. This chapter is published under the Creative Commons Attribution (CC BY 4.0) licence. Anyone may reproduce, distribute, translate and create derivative works of this chapter (for both commercial and non-commercial purposes), subject to full attribution to the original publication and authors. The full terms of this licence may be seen at http://creativecommons.org/licences/by/4.0/legalcode
} 


\section{Introduction}

Most modern health care is heavily dependent on e-health, including record keeping, targeted information sharing and digital diagnostic and imaging techniques. The Models of Child Health Appraised (MOCHA) project therefore contained a special work package looking at this issue.

The foundations are strong. The first electronic health record (EHR) application in child health in Europe was for immunisation scheduling and recording more than 55 years ago in the United Kingdom (Galloway, 1963). Moreover, it was fully operational as opposed to a trial, and was evaluated and found to have a sound economic case as it reduced health service costs as well as reducing morbidity (Saunders, 1970). This success attracted attention and was soon replicated in other localities across the UK, and for other preventive child health services where it showed major equity achievements (Chesham, Rigby, \& Shelmerdine, 1975). It was then rationalised as a national system for the UK covering immunisation, preschool screening and school health (Rigby, 1987). The value of electronic records in ensuring that children (and other vulnerable patients) were not overlooked in service was highlighted (Rigby, 2004), and principles specifically related to child health informatics were promoted (Blair \& Rigby, 2004).

However, the good news story did not last. Within the UK, political fashions came to prevail, and the national system was abandoned in favour of devolving computing policy to regions and also reducing central programmes in favour of embedding children's preventive care into generic primary care services and their generic computer support. Meanwhile in many locations across parts of the rest of Europe, similar systems were apparently steadily developed. However, as this was not seen at the time as significant health service innovation or scientific application, and evaluation was not considered necessary (Rigby, 2001), nothing entered the scientific health literature, and the national scenarios cannot readily be reconstructed.

\section{The Current Limited Evidence and Knowledge Base}

The current situation is that the impetus and scientific lead have been lost, and primary care child health computing is gaining modest ground as a new subject. So much so, in fact, that new pilots are being conducted and published which unknowingly rediscover facts of earlier decades, such as Atchison, Zvoc, and Balakrishnan (2013). However, there is still no scientific knowledge base for optimal system content and function in child primary care.

The MOCHA team has undertaken a literature review. Within Europe, there is no comprehensive knowledge base and very little literature on validated benefits of use or guidance on design. From the United States, the literature is mainly from professional sources seeking agreement and proof-in-use of a children's EHR data and design set, for example Dufendach et al. (2015), Spooner (2012), and Wald, Haque, and Rizk (2018), though primarily from a hospital viewpoint, but again underpinning the lack of assessed evidence-based approaches. The MOCHA project has therefore sought to find out the current situation. 


\section{Use of EHRs for Children in Primary Care}

An initial action for MOCHA was to assess current use of EHRs in children's primary care. An early enquiry though the project's Country Agents was therefore of the extent of usage of EHRs in primary care practice for children. The answers were collated and published (Rigby, Kühne, Greenfield, Majeed, \& Blair, 2018), and the key finding is shown in Figure 14.1. They correlate well with the findings of a slight earlier study by Grossman et al. (2016) for a smaller number of countries and using a different data gathering network.

This shows that for much of Northern and Western European countries EHRs are in regular use, as applies also in some new member states, but Greece and the Baltic countries were lagging behind. However, the methodology was not able to assess the nature and intensity of use, nor the functionality. But it was able to ask about the design or specification process, and whether commercial acquisition or in-house design; only one country was able to say that children's services and data needs had been a prime consideration.

But the project also looked at the use of case-based child public health EHRs, namely, systems that kept key immunisation and public health data but not a full medical record of illness and treatment.

Figure 14.2 shows the pattern of provision of these, and it is more varied but not complimentary in that countries without one system are not stronger with the other. Indeed, two of the countries with no primary care EHR use shown in Figure 14.1, Greece and Latvia, do not have a public health EHR system either.

For these systems, the study was able to ask for a summary of functionality, and the map shows that most covered health screening examinations and immunisation.

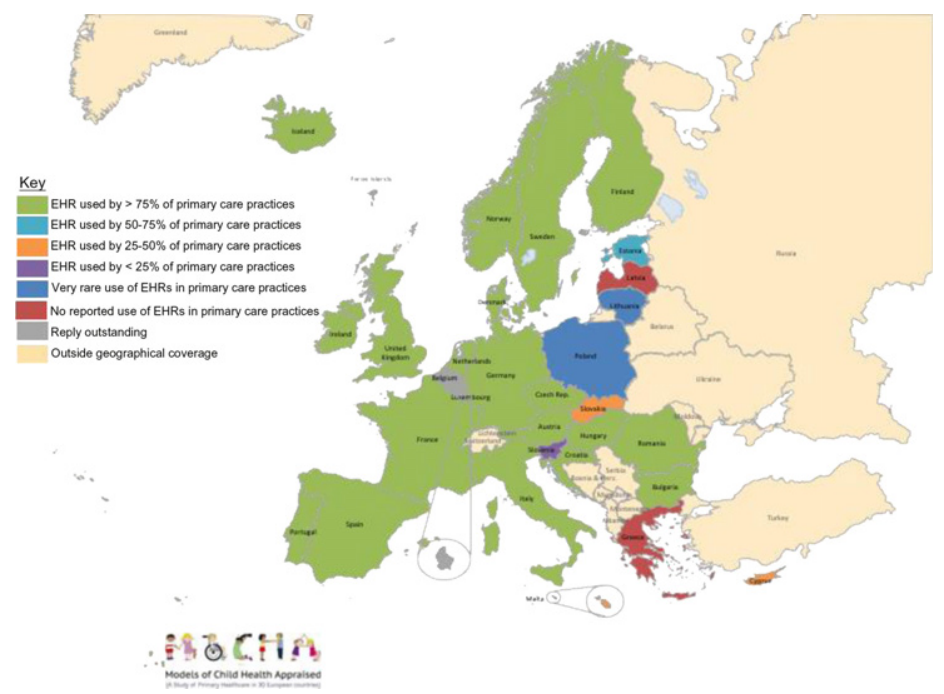

Figure 14.1. Use of EHRs in delivery of primary care for children. Source: MOCHA survey data; Base map from FreeVectorMaps.com 


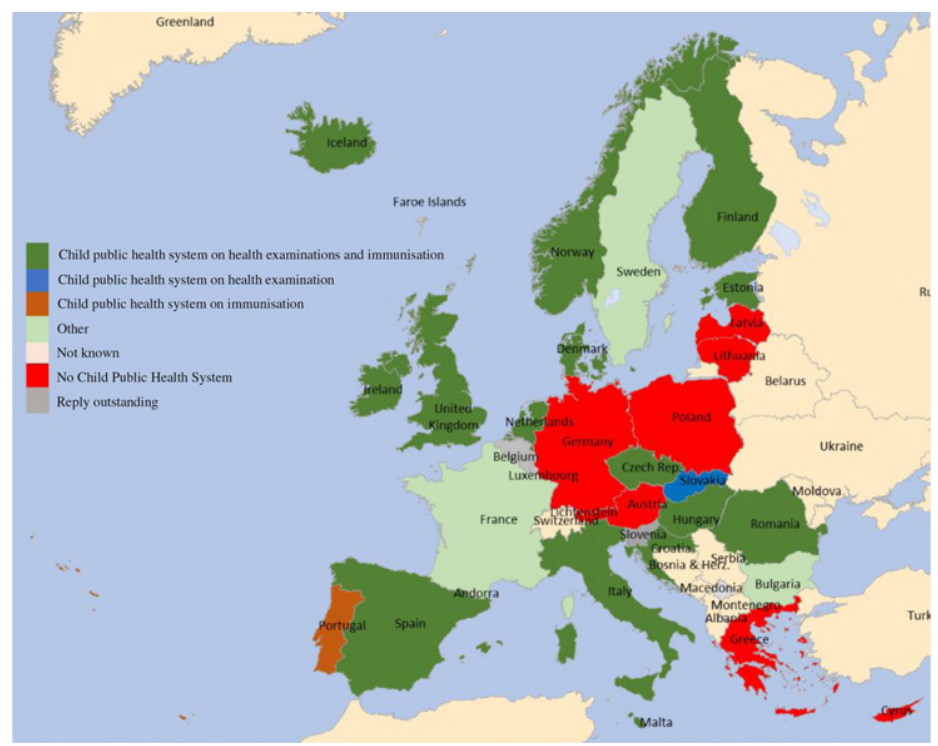

Figure 14.2. Use of child public health EHRs in Europe. Source: MOCHA survey data; Base map from FreeVectorMaps.com

Table 14.1. Functionality and data exchange of child public health systems.

\begin{tabular}{l|l|l}
\hline $\begin{array}{l}\text { System Directly Schedules } \\
\text { Appointments }\end{array}$ & \multicolumn{1}{|c|}{$\begin{array}{c}\text { System Advises Provider of } \\
\text { Children Overdue }\end{array}$} & \multicolumn{1}{|c}{$\begin{array}{c}\text { Passive } \\
\text { Record }\end{array}$} \\
\hline Czech Republic & Czech Republic & Croatia \\
Denmark & Denmark & (SA) \\
Estonia & Estonia & Finland \\
Iceland & Hungary (SA) & Malta (SA) \\
Spain & Iceland & UK \\
UK (Northern Ireland and & Ireland (SA) & \\
Scotland) (SA) & Italy & \\
& Norway & \\
& Romania & \\
& Spain & \\
& UK (England) (SA) & \\
\hline
\end{tabular}

Note: All use a form of automated data exchange unless marked Stand Alone (SA).

Table 14.1 then shows whether the systems were active in supporting attendance monitoring or were merely passive repositories. In the light of the early UK case study earlier in the chapter, it is noteworthy that England and Wales have a lower level of e-health support in this field than half a century earlier. 


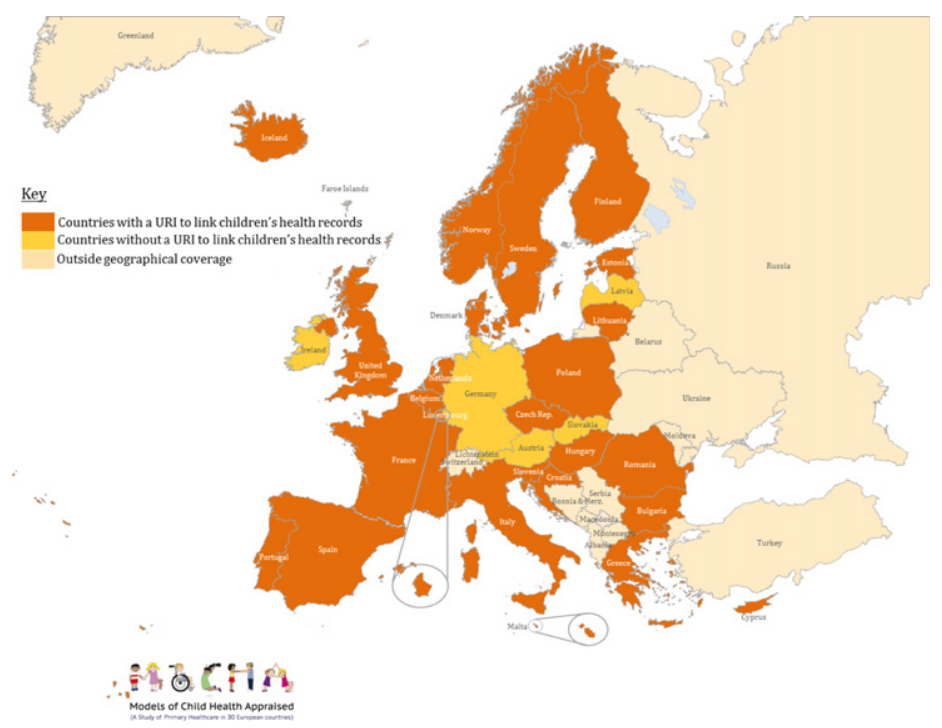

Figure 14.3. Overview of countries with URIs to link children's health records in the EU/EEA. Source: MOCHA survey data; Base map from FreeVectorMaps.com

\section{Unique Identifiers and Record Linkage}

To be safe and effective, electronic record systems need to be able to link data and to be accessible to a concerned clinician, and for this, a national policy and provision of unique record identifier (URI) are important. Furthermore, if these are not issued at birth, there is a serious risk that key data will not be captured and passed on to the primary care provider. The MOCHA team has reported on the current picture and the implications (Kühne \& Rigby, 2016; Kühne, Rigby, Majeed, \& Blair, 2017). The map shown as Figure 14.3 shows the wide coverage of the use of URIs, with only five countries not having these currently; of these five in Austria, Germany and Ireland there are concrete plans and a set timescale for implementation of a URI including for children.

However, not just having a URI in use, but its time of issue is important as mentioned. Figure 14.4 shows the time of issue, with only nine European countries commencing URI-based record linkage form birth. This implies significantly compromised record linkage in the remaining 21 countries.

The final aspect of record linkage is the files or records that can be linked using the one number. In some countries, there is a tradition, and public acceptance, of a comprehensive public services number; in other countries, this is viewed with anxiety, with health and related care being seen as separate and even more confidential. Figure 14.5 shows that just Cyprus and the UK keep health ring fenced, while Croatia, Czech Republic, Greece, Luxembourg and Spain have health and social care or welfare services within the group. 


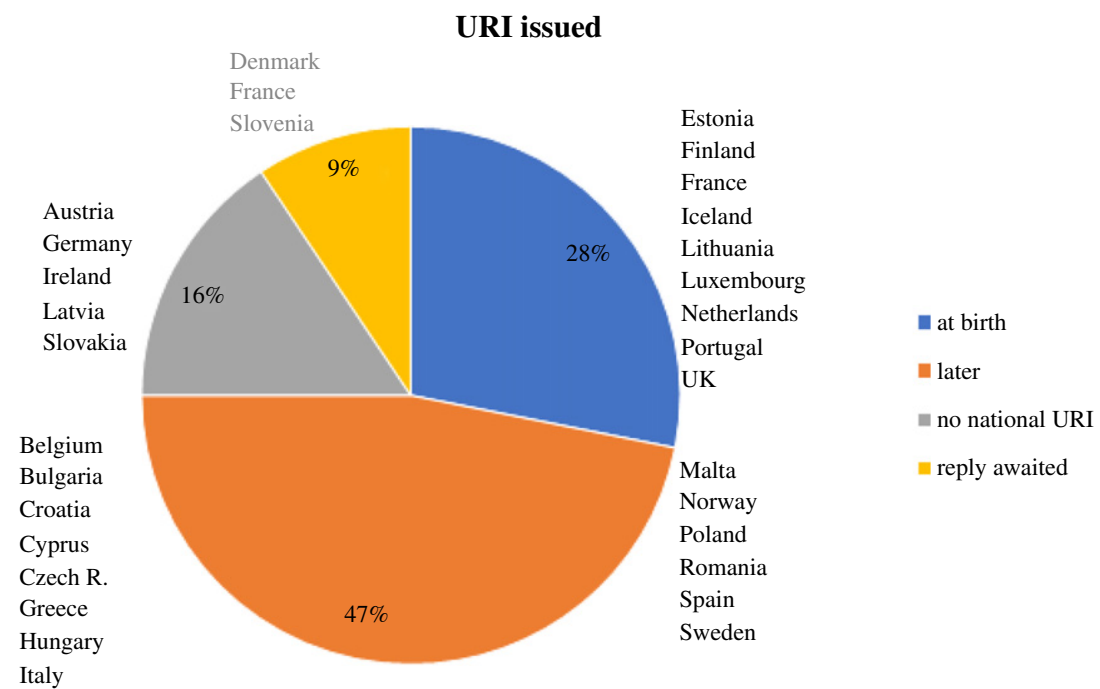

Figure 14.4. Overview on when the URI is issued.

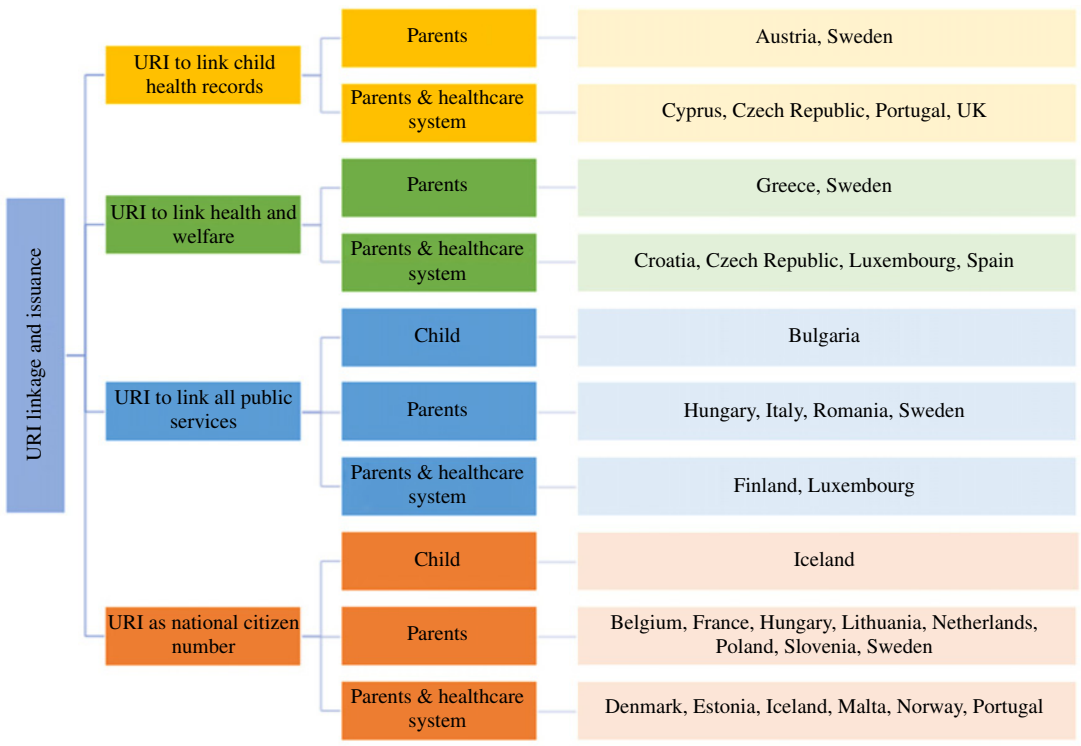

Figure 14.5. Overview on national issuing process and URI function.

The remaining 18 countries have either a public services number or a citizen identifier used for all purposes.

The final item that can be drawn from Figure 14.5 is that some countries issue the number in parallel to the health system, but none informs only the 
health system. Bulgaria and Iceland issue it to the newborn child, which may seem perplexing initially, but it is in fact an underscoring of the parents' role as custodians with a duty of care for the child as opposed to 'owning' the child. All of the other countries issue the Identifier to the parents or the parents and the healthcare system.

\section{Practical and Operational Record Linkage}

Electronic Health Data Exchange is the automated transfer (within strict protocols) of electronic data from one system to another (e.g. from maternity hospital to primary care practitioner, from practitioner immunising a child to a public health monitoring system, or between professionals sharing care for a child). It may be by electronic messaging, regular downloads and uploads or by ongoing real-time linkage. The purpose is to ensure that complementary systems are rapidly, reliably and accurately updated, without the need for data re-entry. To this end, the MOCHA team enquired whether there were any nationally specified electronic data messaging or structured data transfer regarding children's health records based on standards and whether there were any established means of sharing electronic records data among care providers. Table 14.2 reports the organisational linkages for data exchange reported for each country, and Table 14.3 reports the types of child health data exchanged; these have also been published (Rigby, Greenfield et al., 2018).

However, a different view on the same topic comes from the operational viewpoint. School health services (SHSs) provide a useful study area. Chapter 11 has quoted liaison with health services, and data management and records, as SHS quality standards, yet Table 14.2 shows that only four countries have structured data exchange with SHSs. So we also enquired about school health record keeping (not solely electronic records). Table 14.4 shows the data received:

Of the countries reporting, all but one keep records within school health, and three have a form of sharing with primary care. However Figures 14.6 and 14.7 show that there is practical liaison in some countries.

These results show the pattern for general health issue liaison, with variation between those countries which have a high degree of separation and those with some intended linkage to seek a holistic approach. Enquiries were also made as to the existence and use in countries of data standards. Many countries reported agreed national standards or protocols of the design of EHRs and data exchange, but very little use of international standards (Rigby, Kühne, Greenfield, \& Deshpande, 2018). The lack of use of standards underscores how little has been completed regarding children's health data and, as covered in the literature review and the issues, raised in the American policy literature cited there.

The real test, though, can be in practical situations. The case of access to immunisation history for a child injured at school was taken by the MOCHA project as a suitable policy-framing vignette. The picture which resulted is shown in Figure 14.8. 
Table 14.2. Overview on organisational linkages electronic record data sharing.

\begin{tabular}{cccc}
\hline Country Hospitals & $\begin{array}{c}\text { Homel } \\
\text { Community } \\
\text { Care } \\
\text { Providers }\end{array}$ & $\begin{array}{c}\text { Social Schools } \\
\text { Care }\end{array}$ & $\begin{array}{c}\text { Any Other Agency } \\
\text { (Mainly Registries } \\
\text { Local Systems } \\
\text { Funding) }\end{array}$ \\
\hline
\end{tabular}

\section{Austria}

Bulgaria

Croatia

Cyprus

Czech

Republic

Denmark

Estonia

Finland

France

Germany

Greece

Hungary

Iceland

Ireland

Italy

Latvia

Lithuania

Malta

Netherlands

Norway
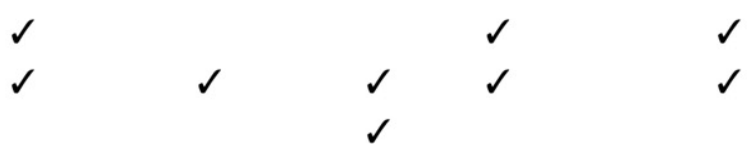

Poland

Portugal

Romania

Slovakia

Spain

Sweden
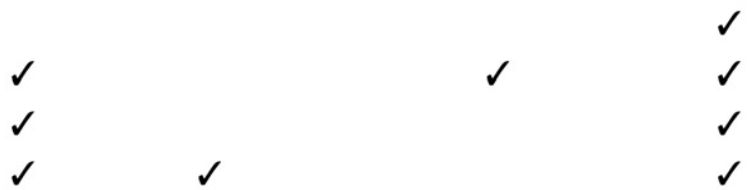

United

Kingdom

Total 
Table 14.3. Overview on types of electronic health data exchanged.

\begin{tabular}{|c|c|c|c|c|c|c|c|}
\hline Country & $\begin{array}{l}\text { No Reported Data } \\
\text { Exchange }\end{array}$ & \multicolumn{6}{|c|}{ Data Set Exchange or Messaging } \\
\hline Bulgaria & $\checkmark$ & & & & & & \\
\hline Croatia & & & & & $\checkmark$ & & \\
\hline $\begin{array}{l}\text { Czech } \\
\text { Republic }\end{array}$ & $\checkmark$ & & & & & & \\
\hline Denmark & & $\checkmark$ & $\checkmark$ & $\checkmark$ & $\checkmark$ & $\checkmark$ & \\
\hline Estonia & & $\checkmark$ & $\checkmark$ & $\checkmark$ & $\checkmark$ & $\checkmark$ & \\
\hline Finland & $\checkmark$ & & & & & & \\
\hline Hungary & & $\checkmark$ & & & & & \\
\hline Iceland & & $\checkmark$ & $\checkmark$ & & $\checkmark$ & & \\
\hline Ireland & & $\checkmark$ & & $\checkmark$ & $\checkmark$ & & \\
\hline Italy & $\checkmark$ & & & & & & \\
\hline Latvia & $\checkmark$ & & & & & & \\
\hline Lithuania & $\checkmark$ & & & & & & \\
\hline
\end{tabular}


Table 14.3. (Continued)

\begin{tabular}{|c|c|c|c|c|c|c|c|}
\hline \multirow[t]{2}{*}{ Country } & \multirow{2}{*}{$\begin{array}{l}\text { No Reported Data } \\
\text { Exchange }\end{array}$} & \multicolumn{6}{|c|}{ Data Set Exchange or Messaging } \\
\hline & & $\begin{array}{l}\text { Data on } \\
\text { Newborn }\end{array}$ & $\begin{array}{l}\text { Data on Hospital } \\
\text { Discharge }\end{array}$ & $\begin{array}{l}\text { Home Visiting } \\
\text { Nurses }\end{array}$ & Immun. & $\begin{array}{c}\text { Preventive or } \\
\text { Routine Exams }\end{array}$ & $\begin{array}{c}\text { Possible } \\
\text { Maltreatment }\end{array}$ \\
\hline Malta & $\checkmark$ & & & & & & \\
\hline Netherlands & & $\checkmark$ & $\checkmark$ & $\checkmark$ & $\checkmark$ & $\checkmark$ & $\checkmark$ \\
\hline Norway & & & & & $\checkmark$ & & \\
\hline Poland & $\checkmark$ & & & & & & \\
\hline Portugal & & $\checkmark$ & $\checkmark$ & $\checkmark$ & $\checkmark$ & $\checkmark$ & $\checkmark$ \\
\hline Romania & $\checkmark$ & & & & & & \\
\hline Slovakia & $\checkmark$ & & & & & & \\
\hline Spain & & $\checkmark$ & $\checkmark$ & & & & \\
\hline \multicolumn{8}{|l|}{ Sweden } \\
\hline UK & $\checkmark$ & & & & & & \\
\hline Total & 16 & 8 & 6 & 5 & 8 & 4 & 2 \\
\hline
\end{tabular}


Table 14.4. What is the policy in your country for health professionals of the school health service (SHS) in keeping their own health records?

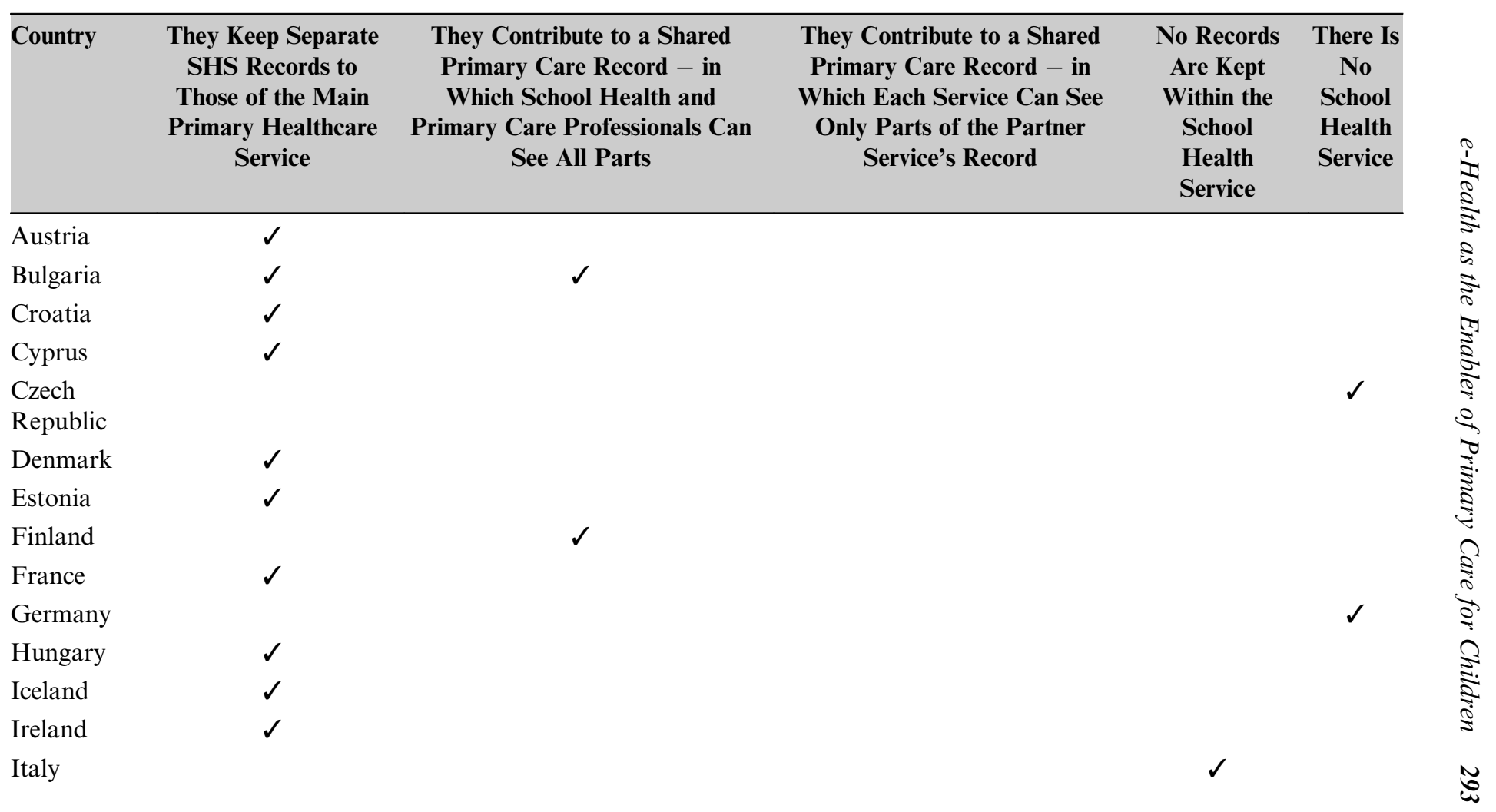


Table 14.4. (Continued)

\begin{tabular}{|c|c|c|c|c|c|}
\hline Country & $\begin{array}{l}\text { They Keep Separate } \\
\text { SHS Records to } \\
\text { Those of the Main } \\
\text { Primary Healthcare } \\
\text { Service }\end{array}$ & $\begin{array}{l}\text { They Contribute to a Shared } \\
\text { Primary Care Record - in } \\
\text { Which School Health and } \\
\text { Primary Care Professionals Can } \\
\text { See All Parts }\end{array}$ & $\begin{array}{l}\text { They Contribute to a Shared } \\
\text { Primary Care Record - in } \\
\text { Which Each Service Can See } \\
\text { Only Parts of the Partner } \\
\text { Service's Record }\end{array}$ & $\begin{array}{c}\text { No Records } \\
\text { Are Kept } \\
\text { Within the } \\
\text { School } \\
\text { Health } \\
\text { Service }\end{array}$ & $\begin{array}{l}\text { There Is } \\
\text { No } \\
\text { School } \\
\text { Health } \\
\text { Service }\end{array}$ \\
\hline Latvia & $\checkmark$ & & & & \\
\hline Lithuania & $\checkmark$ & & & & \\
\hline Malta & $\checkmark$ & & & & \\
\hline Netherlands & $\checkmark$ & & & & \\
\hline Norway & $\checkmark$ & & & & \\
\hline Poland & $\checkmark$ & & & & \\
\hline Portugal & $\checkmark$ & & $\checkmark$ & & \\
\hline Romania & $\checkmark$ & & & & \\
\hline Slovakia & & & & & $\checkmark$ \\
\hline Slovenia & $\checkmark$ & & & & \\
\hline Spain & $\checkmark$ & & & & $\checkmark$ \\
\hline Sweden & $\checkmark$ & & & & \\
\hline $\begin{array}{l}\text { United } \\
\text { Kingdom }\end{array}$ & $\checkmark$ & & & & \\
\hline $\begin{array}{l}\text { Total } \\
\text { numbers }\end{array}$ & 21 & 2 & 1 & 1 & 4 \\
\hline
\end{tabular}




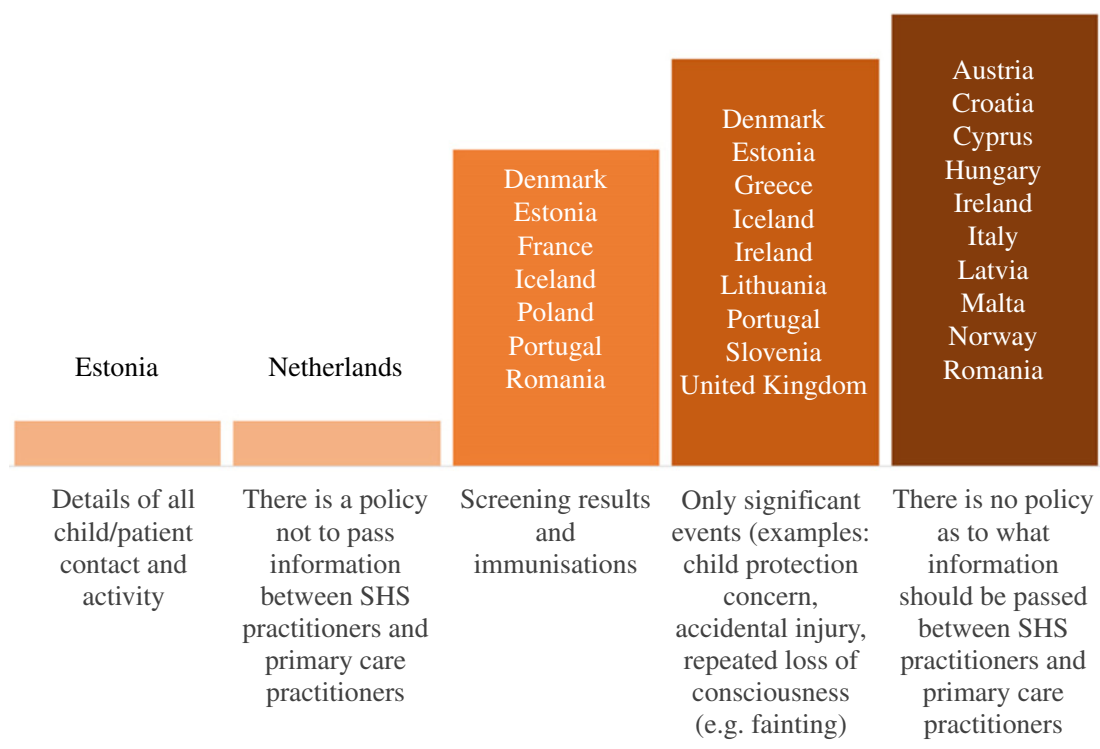

Figure 14.6. If there is not a linked record between primary care services and school health services, what type of information is it policy to pass from the SHS practitioner to the primary care practitioner?

There are quite important societal, ethical and child well-being issues contained in these varied national responses.

Finally, on the topic of Electronic Records, the study within MOCHA considered the ability of a child to see his/her own records. The answers are shown in Figure 14.9.

However, a different situation arises when a child (up to age 18) feels that there are sensitive items in his/her health record which he/she would not want his/her parents to see. Indeed, this might be a barrier to seeking medical help. The reverse situation therefore addresses whether a child could block parental access. The answers to this are shown in Figure 14.10.

\section{New e-Health Media}

Recognising that new media and social media have an increasingly important role in enabling children and young people to access advice, and on occasions, virtual services, this field has been one of the objects of study for the MOCHA project.

\section{Websites}

There are numerous websites that children can access regarding health matters, whether or not designed for children. It is also known that many websites can be 
Shared record fully accessible to health professional staff in the SHS
- Estonia, Finland, Iceland

- France
Restricted shared records giving access to parts of the primary care record only; or portal access by SHS professionals to defined parts of the primary care record.

\section{Automatic notification of key events \\ (including immunisation and \\ allergies) (electronically or by standard form) from primary care to School Health Service}

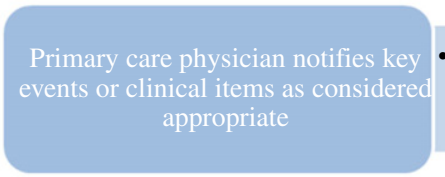

Primary care does not share information with the School Health Services
- Estonia, Lithuania, United Kingdom

- Bulgaria, Croatia, Denmark, Estonia, France, Italy, Lithuania, Norway, Poland, Portugal, Romania, Slovenia

Figure 14.7. Looking at communication in the other direction, from primary care to school health service professionals, what is the policy of information sharing from primary care to the school health service?

malicious, and others can be ineffectual or containing poor advice (Forsström \& Rigby, 2000). Significant years later, few countries have developed means of validating and protecting children against poor or dangerous websites. Enquiries of the MOCHA countries identified seven with processes in place, as shown in Table 14.5.

The HON Code refers to a generic initiative run by the Health on the Net Foundation (https://www.hon.ch/en/).

\section{Apps}

An even more modern form of health advice and interaction is via smartphone apps. While these can be innovative and helpful, they can also be unscientific or even malicious, and they can surreptitiously gather use data. There has been some discussion with the European Commission as to whether to seek to create standards. MOCHA studied how many countries already had safeguards in place and found that was only in five countries and some of these were not particularly robust (Table 14.6): 
Urgent treatment centres have access to primary care medical records

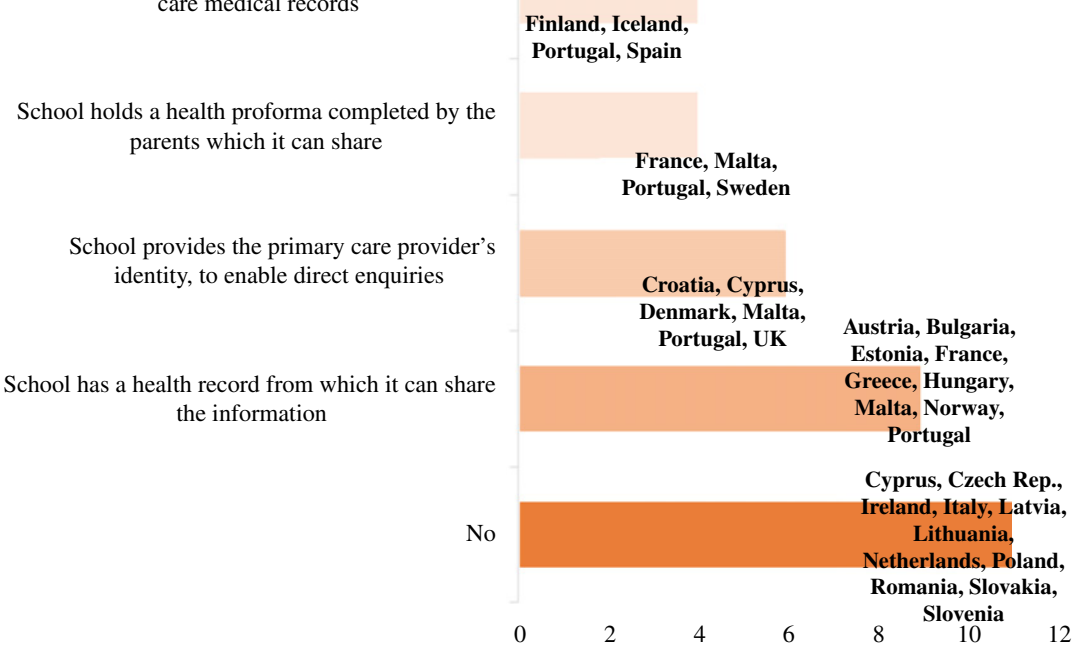

Figure 14.8. If a pupil sustains an injury in school that needs urgent medical treatment, is the school able to supply to the urgent treatment centre: the child's tetanus immunisation status?

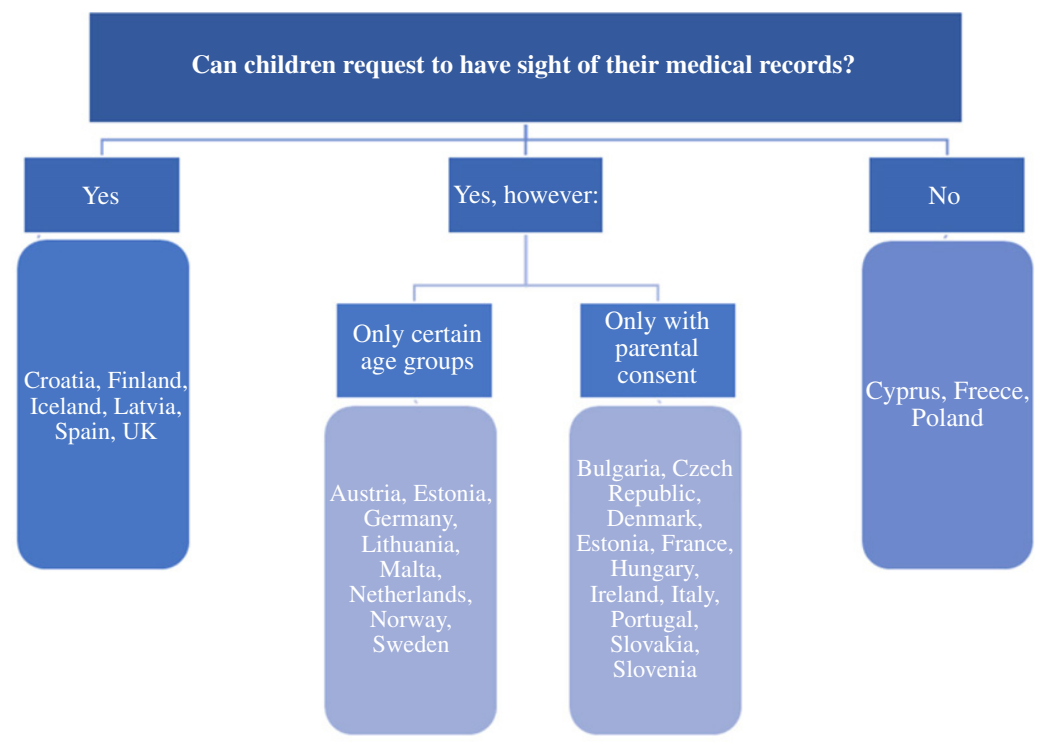

Figure 14.9. According to the policy for record keeping in your country, can a child request to have sight of their medical records? 


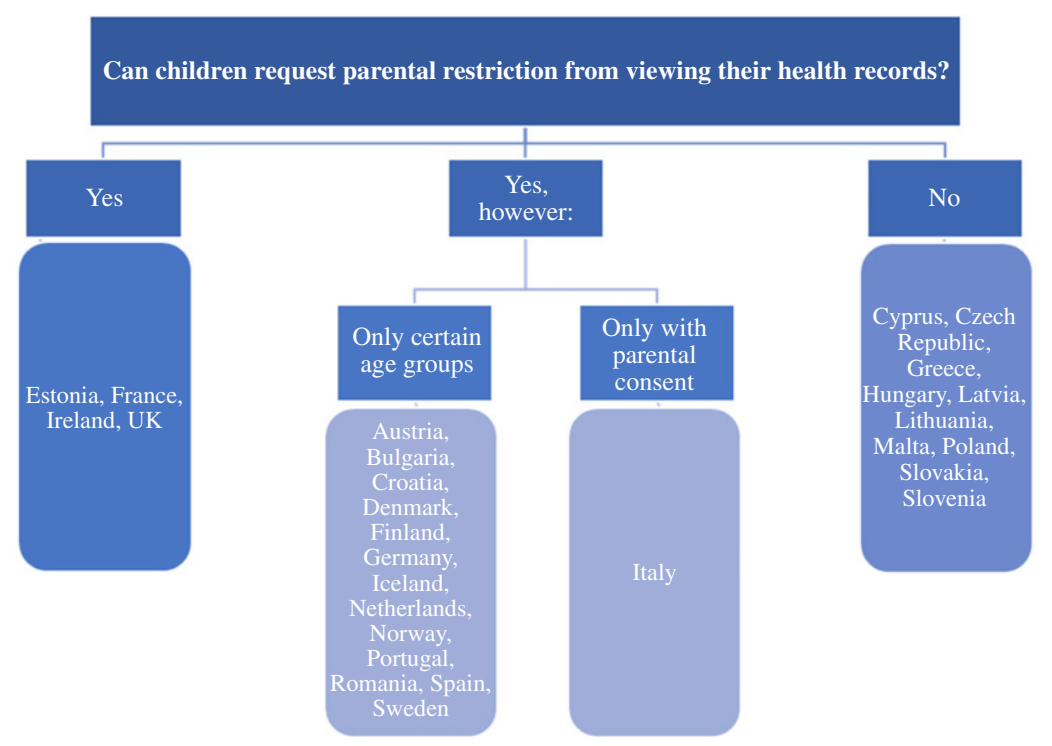

Figure 14.10. Countries where a child can specify that their parents may not see part of their medical records.

\section{External Collaboration}

Finally, this work can be contextualised in two respects. The European Centre for Disease Control (ECDC) has a major interest in Immunisation Information System (IIS) provision. IISs keep records of individuals' immunisation history across all ages and including travel and occupational vaccine protections. But childhood immunisation forms a core part of this. In 2017, ECDC undertook a Europe-wide survey, which not only included the use of IISs in each country, but also included study of URIs (ECDC, 2017). The findings of ECDC have been matched against the MOCHA findings, and the results are mutually supportive. This not only strengthens the perception of the importance of these practical e-health principles, but also enables joint consideration.

\section{HL7 Foundation and Trillium II Project}

The HL7 Foundation is a key international body in the setting of health data standards. It is also currently running the Trillium II project, (https://trillium2. $\mathrm{eu} /$ ) to develop data and content standards for an International Patient Summary. This project has seen the omission from its work hitherto of childspecific summaries and has agreed a formal collaboration with the MOCHA project to pursue joint work on standards for child health records, data items and processes. This is important in its own right and starts to address what has already been identified as an unmet need. As the MOCHA project comes to an 
Table 14.5. MOCHA countries with website accreditation process in place.

\begin{tabular}{ll}
\hline Country & Accreditation Process Reported \\
\hline Austria & HON code \\
Croatia & No specific details given \\
Estonia & No specific details given \\
France & HON code \\
Germany & HON code \\
Portugal & Institutional websites, accredited by providers \\
Spain & HON code, MedCIRCLE [...] \\
United Kingdom & The Information Standard \\
\hline
\end{tabular}

Table 14.6. MOCHA countries with apps accreditation process reported.

\begin{tabular}{ll}
\hline Country & Accreditation Process Reported \\
\hline Estonia & Child helpline service app \\
Germany & Unofficial, internal regulation \\
Portugal & No specific details given \\
Slovenia & $\begin{array}{l}\text { Slovenian Institute of Quality and Metrology (SIQ) } \\
\text { certifies apps as any other medical equipment }\end{array}$ \\
Spain & Processes vary across autonomous regions \\
United Kingdom & MHRA, National Information Board \\
\hline
\end{tabular}

end, joint workshops with the Trillium II project, and with ECDC, are seeking to take forward this work, and for some of the objectives of MOCHA to be continued in that forum.

\section{Conclusion}

e-Health is a large subject. It also sits in a peculiar position in policy development. IT services should always be in the background, as supporters of modern care delivery. However, new information technologies have the power to transform radically how services can be and are delivered - as has already happened in particular with civil aviation, financial services and retailing. New opportunities and mobilities arise, and information silos can be broken down - though new inequalities and other perverse effects have to be anticipated and avoided.

More recently, online services of the Internet and smartphone apps have enabled the citizen (including children) to access information, and initiate 
actions, in ways which can be enlightening and empowering, or which can be dangerous and disruptive. The challenge for policy-makers and practitioners is to be aware and to lead on innovative harnessing of new technologies and to protect the citizen and patient against new harms.

The work of MOCHA on e-health to support modern models of primary care for children has shown a largely worrying picture. Though basic electronic records are widespread in much of Europe, opportunities to initiate positive innovation seems restricted to just a few countries. Protection against harm is even more unusual. Yet out of this, and the compilation and publication of situation analyses, some synergy is emerging of a wish to be more positive in developing e-health to support primary care for children.

\section{References}

Atchison, C., Zvoc, M., \& Balakrishnan, R. (2013). The evaluation of a standardized call/recall system for childhood immunizations in Wandsworth, England. Journal of Community Health, 38(3), 581-587. doi:10.1007/s10900-013-9654-4.

Blair, M., \& Rigby, M. (2004). Principles and purpose for child health informatics. In M. Rigby (Ed.), Vision and value in health information (pp. 108-120). Oxford: Radcliffe Medical Press (ISBN 185775863 3).

Chesham, I., Rigby, M. J., \& Shelmerdine, H. R. (1975). Paediatric screening. Health and Social Service Journal, 85, 293-294.

Dufendach, K. R., Eichenberger, J. A., McPheeters, M. L., Temple, M. W., Bhatia, H. L., Alrifai, W., et al. (2015). AHRQ comparative effectiveness technical briefs. Core functionality in pediatric electronic health records. Rockville, MD: Agency for Healthcare Research and Quality. Retrieved from https://www.ncbi.nlm.nih. gov/books/NBK293626/

European Centre for Disease Control. (2017). Technical report - Immunisation information systems in the EU and EEA results of a survey on implementation and system characteristics ECDC Stockholm. Retrieved from https://ecdc.europa.eu/sites/ portal/files/documents/immunisation-systems.pdf

Forsström, J., \& Rigby, M. (2000). TEAC-health - Research-based recommendations for European certification of health telematics services. In A. Hasman, B. Blobel, D. Dudeck, R. Engelbrecht, G. Gell, H. U. Prokosch (Eds.), Medical infobahn for Europe: Proceedings of MIE2000 and GMDS2000 (pp. 288-292). Amsterdam: IOS Press.

Galloway, T. McL. (1963). Management of vaccination and immunization procedures by electronic computer. Medical Officer, 109, 232.

Grossman, Z., del Torso, S., van Esso, D., Ehrich, J. H. H., Altorjai, P., Mazur, A., ... Hadjipanayis, A. (2016). Use of electronic health records by child primary healthcare providers in Europe; Child: Care, health and development. Child Care Health and Development, 42(6), 928-933. doi:10.1111/cch.12374. Epub 2016 Jul 10.

Kühne, G., \& Rigby, M. (2016). Description and analysis of current child health electronic record keeping across Europe. Retrieved from http://www.childhealthservicemodels.eu/publications/technical-reports/

Kühne, G., Rigby, M. J., Majeed, A., \& Blair, M. E. (2017). Towards safe and efficient child primary care - Gaps in the use of unique identifiers in Europe. 
In A. Ugon et al. (Eds.), Informatics for health: Connected citizen-led wellness and population health (pp. 930-934). Amsterdam: IOS Press.

Rigby, M. (2001). Evaluation: 16 powerful reasons why not to do it - And 6 overriding imperatives. In V. Patel, R. Rogers, R. Haux (Eds.), Medinfo 2001: Proceedings of the 10th. world congress on medical informatics (pp. 1198-1202). Amsterdam: IOS Press.

Rigby, M. (2004). Information as the patient's advocate. In M. Rigby (Ed.), Vision and value in health information (pp. 57-67). Oxford: Radcliffe Medical Press (ISBN 185775863 3).

Rigby, M. J. (1987). The national child health computer system. In A. Macfarlane (Ed.), Progress in child health (Vol. 3). Abingdon: Churchill Livingstone.

Rigby, M., Greenfield, R., Majeed, A., \& Blair, M. (2018). Variation of national policies on controlled sharing with partner services of children's primary care data. Retrieved from http://www.childhealthservicemodels.eu/publications/technicalreports/

Rigby, M., Kühne, G., Greenfield, R., \& Deshpande, S. (2018). Future achievable potential models of child health electronic record systems to support care delivery. Retrieved from http://www.childhealthservicemodels.eu/publications/deliverables/

Rigby, M., Kühne, G., Greenfield, R., Majeed, A., \& Blair, M. (2018). Extent of use of electronic records in children's primary care and public health in Europe. Studies Health Technology and Informatics, 247, 930-934 (PMID: 29678097).

Saunders, J. (1970). Results and costs of a computer-assisted immunization scheme. British Journal of Social and Preventive Medicine, 24, 187-191.

Spooner, S. A. (2012). We are still waiting for fully supportive electronic health records in pediatrics. Pediatrics, 130(6).

Wald, J., Haque, S., \& Rizk, S. (2018). Enhancing health IT functionality for children the 2015 children's EHR format. Pediatrics, 141, 1-7. 